\title{
Effect of vigabatrin on sedation and cognitive function in patients with refractory epilepsy
}

\author{
R A Gillham, J Blacklaw, P J W McKee, M J Brodie
}

Department of Clinical Psychology, Institute of

Neurological Sciences, Southern General Hospital and Epilepsy

Research Unit,

University

Department of

Medicine and

Therapeutics,

Western Infirmary,

Glasgow, UK

R A Gillham

J Blacklaw

P J W McKee

$M$ J Brodie

Correspondence to:

Dr $M$ J Brodie, Epilepsy

Research Unit, Department

of Medicine and

Therapeutics, Western

Therapeutics, Western

6NT, United Kingdom

Received 31 July 1992 and

in revised form

15 January 1993.

Accepted 1 February 1993

\begin{abstract}
Twenty-four patients with refractory epilepsy on one or more antiepileptic drugs were given additional vigabatrin ( $1 \mathrm{~g}$ twice daily for six weeks, followed by $1.5 \mathrm{~g}$ twice daily for a further six weeks) and matched placebo in a double blind, randomised, crossover study. A battery of neuropsychological tests was administered at baseline and at weeks two, six and 12 of both treatment periods. No significant differences were found between vigabatrin and placebo at any time point for any of the objective tests of cognitive function. Patients, however, reported a greater degree of sedation after two and six weeks on vigabatrin than during the equivalent placebo phase $(p<0.01)$, although no such difference was apparent at 12 weeks. Follow up over a mean of 14.75 months in 12 responders, who continued on vigabatrin, revealed a significant improvement (all $p<0.01$ ) on each of three composite scales (three psychomotor tests, four memory tests, three self rating scales) compared with their scores during the double blind trial. Vigabatrin did not cause cognitive impairment either acutely or in the long term. Phased introduction, however, seems a prudent policy to allow tolerance to early subjective sedation.
\end{abstract}

$(尹$ Neurol Neurosurg Psychiatry 1993;56:1271-1275)

Table 1 Clinical characteristics of 24 patients with refractory epilepsy

\begin{tabular}{clllll}
\hline Patient & Sex & $\begin{array}{l}\text { Age } \\
\text { (years) }\end{array}$ & Seizure type & $\begin{array}{l}\text { Duration } \\
\text { (years) }\end{array}$ & Treatment \\
\hline 1 & $\mathrm{~F}$ & 24 & GTCS & 16 & CBZ \\
2 & $\mathrm{~F}$ & 53 & CPS & 43 & CBZ \\
3 & $\mathrm{M}$ & 27 & CPS/GTCS & 8 & CBZ/NPA \\
4 & $\mathrm{~F}$ & 38 & CPS/GTCS & 24 & CBZ \\
5 & $\mathrm{~F}$ & 24 & CPS/GTCS & 24 & CBZ/PRIM \\
6 & $\mathrm{~F}$ & 17 & CPS/GTCS & 6 & CBZ \\
7 & $\mathrm{~F}$ & 31 & CPS & 30 & CBZ/PRIM \\
8 & $\mathrm{~F}$ & 45 & CPS & 42 & PHT/PB \\
9 & $\mathrm{~F}$ & 46 & CPS/GTCS & 22 & VPA/PB \\
10 & $\mathrm{~F}$ & 27 & CPS & 20 & PHT \\
11 & $\mathrm{~F}$ & 36 & CPS/GTCS & 33 & CBZ/VPA \\
12 & $\mathrm{~F}$ & 34 & CPS/GTCS & 23 & CBZ \\
13 & $\mathrm{~F}$ & 20 & CPS/GTCS & 9 & CBZ/VPA \\
14 & $\mathrm{~F}$ & 32 & CPS & 30 & PHT/PRIM \\
15 & $\mathrm{M}$ & 49 & CPS & 27 & CBZ/PRIM \\
16 & $\mathrm{M}$ & 22 & GTCS & 20 & CBZ/PHT \\
17 & $\mathrm{M}$ & 43 & CPS/GTCS & 8 & CBZ/PRIM \\
18 & $\mathrm{M}$ & 26 & CPS & CBZ \\
19 & $\mathrm{~F}$ & 24 & CPS/GTCS & 4 & CBZ \\
\hline 20 & $M^{\star}$ & 26 & CPS/GTCS & 6 & CBZ \\
21 & $M^{\star}$ & 35 & CPS/GTCS & 9 & CBZ/PHT \\
\hline 22 & M & 44 & CPS/GTCS & 9 & CBZ/PRIM \\
23 & $\mathrm{~F} \dagger$ & 27 & CPS & 7 & VPA \\
24 & F十 & 39 & CPS/GTCS & 36 & CBZ \\
\hline
\end{tabular}

*Patients excluded from seizure analysis.

tPatients who failed to complete the study.

GTCS = generalised tonic-clonic seizures; $C P S=$ complex partial seizures; $C B Z=$ carbamazepine; VPA = sodium valproate; $P H T=$ phenytoin, $P R I M=$ primidone; $P B=$ phenobarbital.
Vigabatrin was the first 'designer' drug to be used for the treatment of epilepsy. It is an irreversible suicide inhibitor of $\gamma$-aminobutyric acid (GABA) transaminase, the enzyme responsible for the breakdown of the inhibitory neurotransmitter GABA. ${ }^{1}$ Thus, it increases the concentration of GABA in the brain. Efficacy trials have been largely confined to patients with refractory epilepsy already receiving other antiepileptic drugs. Overall, a $50 \%$ reduction in frequency of the seizures has been reported in around $50 \%$ of treated patients. ${ }^{2-4}$ The benefits were particularly apparent in patients with partial seizures (unpublished observations). ${ }^{5}$ Good, long term efficacy has been reported with the drug over a number of years..$^{6-15}$

The safety of vigabatrin has come under particular scrutiny because it produced intramyelinic oedema in the dog and rat, ${ }^{16-17}$ although there is no evidence in support of a similar lesion in man. ${ }^{41-19}$ Vigabatrin is known to be sedative in some patients, particularly during early treatment. ${ }^{4}$ Few objective data are available on cognitive function, although one non-randomised, non-blinded study with a parallel control group did not support a major deleterious effect with the drug. ${ }^{20}$ In this study, our standard battery of cognitive function tests ${ }^{21-23}$ was administered to patients with refractory epilepsy who were taking part in an add-on, dose ranging, placebo controlled, crossover trial (unpublished observations). Measures were made in the short term and after prolonged administration of vigabatrin in responders.

\section{Methods}

PATIENTS

Twenty-four patients (16 women, 8 men; aged 17-53 years) with refractory epilepsy entered the trial (table 1). Fourteen suffered complex partial seizures with secondary generalisation (PSG), eight had complex partial seizures (CPS) alone and two reported only generalised tonic-clonic seizures (GTCS). Each averaged at least one seizure per week during the three months before recruitment. Eleven patients were being treated with anticonvulsant monotherapy (nine took carbamazepine, one phenytoin, and one sodium valproate) and the other 13 took two drugs in combination (10 had carbamazepine, six primidone, four sodium valproate, four phenytoin, and two phenobarbital). All gave written consent to their participation in the trial, which had the approval of the local ethical committee. 
PROTOCOI

The study was a double blind, randomised, crossover, add-on trial of two consecutive doses of vigabatrin and matched placebo. After an initial four week run-in, two 12-week treatment periods (phase one: six weeks of $1 \mathrm{~g}$ vigabatrin/matched placebo twice daily; phase two: six weeks of $1.5 \mathrm{~g}$ vigabatrin/ matched placebo twice daily) were separated by a four-week washout. Neuropsychological testing was performed immediately before each schedule and after two, six and 12 weeks of treatment. Patients were given individual appointment times, which were kept constant throughout the trial. Patients were asked to take their medication at the same times each day. Seizures were recorded using standard description and frequency charts with which the patients were familiar. At each hospital visit, compliance with medication was checked by a tablet count.

\section{TEST BATTERY}

The test battery consisted of measures of verbal and performance IQ, psychomotor function, visual attention, memory, and subjective side effect rating scales as below:

\section{Intelligence quotients}

The verbal IQ was calculated from the score on the National Adult Reading Test. The performance IQ was calculated by a standard method from the score on Raven's standard progressive matrices.

\section{Psychomotor tests}

The decision time was the time in milliseconds to respond to a light coming on by removing the finger from the base button in a choice reaction time task. The mean of 30 trials was recorded. The movement time was the time in milliseconds to move the finger from the base button to extinguish a light. The mean of 30 trials was recorded.

In another test, an array of small rectangles was displayed on a visual display unit. After a brief period an extra rectangle was added to the array. The patient was required to indicate which it was. The 'threshold' was the minimum time gap in frame units between the presentation of the array and the additional stimulus that the patient required to perceive that an extra rectangle had been added.

Finally, the tracking task measured the amount of time the patient was able to keep on the track of a moving target presented on a visual display unit using a joystick.

Decision and movement time tests were carried out using the choice reaction time facility of the Leeds psychomotor tester. Threshold detection and the tracking task were administered using an Apple IIe microcomputer.

\section{Memory tests}

The forward digit span test measured the maximum number of digits the patient could recall immediately following oral presentation. $\mathrm{He}$ or she was allowed two trials at each level and the task was discontinued when both were failed.

The backward digit span measured the maximum number of digits the patient could recall in reverse order immediately following oral presentation. $\mathrm{He}$ or she was allowed two trials at each level and, again, the task was discontinued when both were failed.

The paired associate learning test measured the number of trials to reach the criterion of three correct answers, when learning three, unrelated word pairs.

In the Rivermead behavioural memory test, the 'screen score' of this standardised psychometric battery was used.

\section{Self reporting scales}

The general health questionnaire was the standard 28 question version, which gave a 'cut off' point for psychiatric cases.

The sedation score assessed the patient's rating of level of alertness using a $10 \mathrm{~cm}$ line where zero was 'wide awake' and 10 'nearly asleep'.

The patient was also presented with a list of 10 commonly reported antiepileptic drug side effects-for example, dizziness, headache, and nausea. He or she rated each one on a $10 \mathrm{~cm}$ line with 'don't have it' at one end and 'very severe' at the other. The distances from the left hand side of the scales were measured in centimetres and summated to produce a subjective side effect score.

\section{DRUG ASSAYS}

Blood was withdrawn at each review appointment for measurement of antiepileptic drug concentrations. Samples were centrifuged immediately and plasma stored at $-20^{\circ}$ for batch analysis. Vigabatrin was extracted into ethyl acetate from plasma heated with dansyl chloride to form a fluorescent derivative at high $\mathrm{pH}$ and quantified using high pressure liquid chromatography with phenyl-GABA as the internal standard. The interassay coefficient of variation over the range $1-100 \mathrm{mg} / 1$ was $5 \%$ and the lower limit of detection was $0.1 \mathrm{mg} / \mathrm{l}$. Concentrations of other antiepileptic drugs were measured by enzyme immunoassay (Emit, Syva, Palo Alto, United States).

\section{STATISTICS}

Analysis of variance was employed to explore the possibility of a practice effect for all tests. Student's $t$ testing for paired values was used to compare placebo and treatment condition scores on the psychomotor and memory tests, because these have been standardised and scores in sample populations are normally distributed. Scores on the three 'self report' scales were compared with the Wilcoxon matched pairs test. Correlations (Spearman) were performed to test the hypothesis that sedation influenced test performances. Comparisons of seizure frequencies between vigabatrin and placebo phases were made using the Wilcoxon rank test for matched pairs. Frequencies of seizures during follow up were compared using Friedman's test. 
The composite scores used in a long term part of the study are Z-scores and may be considered to be normally distributed. These were examined by repeated measures analysis of variance. Paired $t$ tests were then used to identify the point where significant changes had occurred. Significance levels were set conservatively at $1 \%$.

\begin{abstract}
Results
PATIENTS

Twenty-one patients completed the trial; 11 (group 1) took vigabatrin during the first phase, and 10 (group 2) took the placebo first. One patient discontinued treatment because she thought that she was pregnant, another because he felt no benefit after two weeks, and a third following a psychotic episode. $^{24}$
\end{abstract}

\section{SEIZURE CONTROL}

There was a significant overall reduction (median) in partial seizures over the treatment period with $2 \mathrm{~g}$ (placebo 22, vigabatrin 13, p < 0.05, 95\% CI -0.5 to -16.5$)$ but not with $3 \mathrm{~g}$ (placebo 28, vigabatrin 22, not significant, $95 \% \mathrm{CI}-18$ to +11 ) vigabatrin daily compared with placebo. Eight out of 19 patients who documented their episodes satisfactorily, reported a greater than $50 \%$ improvement in seizure frequency. These results will be discussed in detail elsewhere.

\section{DRUG CONCENTRATIONS}

There was large interindividual variation in serum vigabatrin levels. Mean (SD) concentrations of the drug at the same time after dosing were higher following six weeks' treatment with $3 \mathrm{~g}(15.5(8.9) \mathrm{mg} / \mathrm{l})$ than with $2 \mathrm{~g}$ $(13.9(11.2 \mathrm{mg} / \mathrm{l})$ daily. Significant negative correlations were obtained between vigabatrin concentrations and times after dosing with both the $2 \mathrm{~g}(\mathrm{r}=0.75, \mathrm{p}<0.01)$ and $3 \mathrm{~g}$

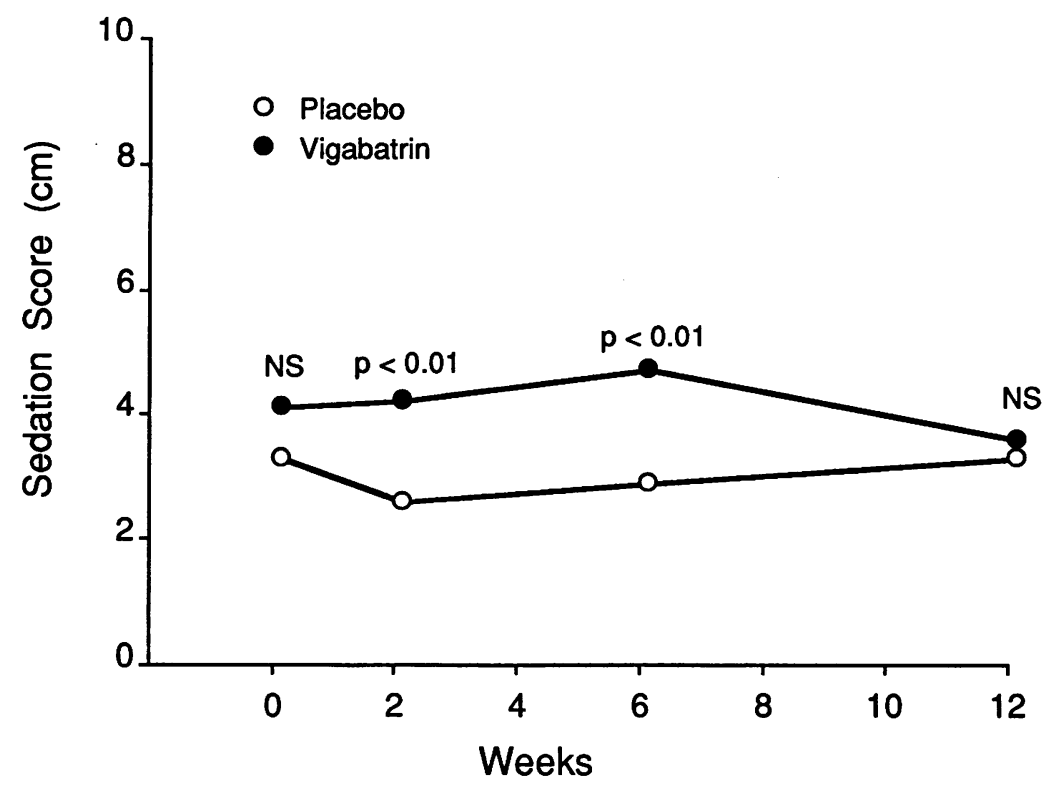

Figure Mean sedation scores during the double blind, placebo controlled part of the study in 21 patients with refractory epilepsy. NS = not significant. $(\mathrm{r}=0.72, \mathrm{p}<0.01)$ doses, suggesting good compliance with treatment. This was supported by the tablet counts. Vigabatrin did not alter total or free concentrations of any concomitant antiepileptic drug (unpublished observations). There were no significant differences in vigabatrin or other antiepileptic drug concentrations between responders ( $>$ $25 \%$ reduction in frequency) and nonresponders following treatment with both doses.

\section{NEUROPSYCHOLOGICAL ASSESSMENT}

Neuropsychological testing and data analysis from the short term study were performed blind to treatment. This was not possible during long term follow up as only patients responding to vigabatrin were included.

\section{Between patient analysis}

There were no significant differences between groups 1 and 2 in terms of age, duration of epilepsy or seizure frequency at base-line. No differences between the two groups were found for any of the neuropsychological measures at base line, or at any of the subsequent testing points. There was an improvement in performance on the tracking task over the first three testings regardless of treatment $(p$ $<0.005$ ). This test was, therefore, excluded from further analysis. No other test revealed a significant practice effect.

Within patient analysis

Scores on vigabatrin were compared with those on placebo. Patients rated their sedation level significantly higher $(p<0.01)$ when they had been taking vigabatrin for two and six weeks compared with placebo. This effect was not sustained at 12 weeks (fig). There were no significant differences between the treatments for any other test in the battery (data available from the authors).

\section{Correlations with sedation score}

During treatment with vigabatrin, the sedation scores correlated significantly with side effect scoring during the sixth and 12th week and with backward digit span during the 12th week (all $p<0.05$ ). Sedation scoring correlated significantly during the placebo phase with the side effect score during the second, sixth and 12th weeks, with decision time and general health questionnaire in the second week and with backward digit span in the 12th week (all $\mathrm{p}<0.05$ ).

\section{Long term follow up}

Twelve patients (mean age 33 years), whose seizure frequency had diminished by more than $25 \%$, were continued on the drug and followed up for a mean of 14.75 months without any subsequent change in antiepileptic medication. Their test scores were converted to standard $(Z)$ scores, with a mean of zero and standard deviation of 1 . Three 'composite' scales were produced, made up of the three remaining psychomotor tests (decision and movement times, threshold detection), the four memory tests (forward 
Table 2 Composite Z-scores (mean 0, SD 1) for long term study in responders

\begin{tabular}{lrlll}
\hline & & Psychomotor & Memory & Self rating \\
\hline Baseline & & -0.14 & -0.42 & 0.19 \\
Placebo & 2 & -0.53 & & 1.02 \\
(weeks) & 6 & -0.56 & & 0.75 \\
& 12 & -0.27 & -0.19 & -0.27 \\
Vigabatrin & 2 & -0.19 & & -0.25 \\
(weeks) & 6 & -0.38 & & -0.32 \\
& 12 & $-1.09^{\mathrm{a}}$ & 0.15 & $-0.91^{\mathrm{f}}$ \\
Follow up & 1 & 0.12 & $-0.84^{\mathrm{d}}$ & -0.48 \\
(months) & 3 & 0.53 & -0.82 & -0.60 \\
& 6 & 0.43 & -0.52 & 0.58 \\
& 9 & 0.92 & 0.08 & -0.45 \\
& 12 & $1.01^{\mathrm{b}}$ & 1.20 & $1.29^{\mathrm{g}}$ \\
& 15 & $1.28^{\mathrm{c}}$ & $1.35^{\mathrm{e}}$ & $0.93^{\mathrm{h}}$ \\
\hline
\end{tabular}

$a-b, a-c ; d-e ; f-g, f-h ; p<0.01$

and backward digit span, paired associate learning, Rivermead test) and the three self report scales (general health questionnaire, sedation and side effect scores). Significant improvement over the follow-up period occurred with all three scales (table 2). This change took place at week 12 of the vigabatrin treatment phase during the placebo controlled trial and the end of follow up for the psychomotor and self rating scales and between the beginning and end of follow up for the memory scale (all $p<0.01$ ). There was no further improvement in seizure control during the follow up period (table 3 ) and no correlation was found between numbers of seizures and cognitive test performances.

\section{Discussion}

TEST SENSITIVITY AND SPECIFICITY

During the first and second leg of the trial there was no significant difference between the group taking vigabatrin and those taking placebo for any test in the battery. There were no changes in performance when the dose of vigabatrin was increased or when patients were changed from placebo to active treatment. This finding is consistent with an early report suggesting that vigabatrin does not produce cognitive impairment. ${ }^{20}$ Such a conclusion, however, cannot be drawn without regard to other possibilities. It could be argued that, although our test battery

Table 3 Seizure frequencies in responders to vigabatrin during long term follow up

\begin{tabular}{|c|c|c|c|c|c|c|}
\hline Visit & Total & $n$ & Partial & $n$ & Tonic-clonic & $n$ \\
\hline Baseline & $\begin{array}{l}17 \cdot 0 \\
(5-55)\end{array}$ & 12 & $\begin{array}{l}15 \cdot 5 \\
(7-55)\end{array}$ & 12 & $\begin{array}{l}5 \cdot 5 \\
(0-46)\end{array}$ & 11 \\
\hline During trial & $\begin{array}{l}13 \cdot 0 \\
(4-98)\end{array}$ & 12 & $\begin{array}{l}14 \cdot 0 \\
(0-90)\end{array}$ & 12 & $\begin{array}{l}3 \cdot 5 \\
(0-11)\end{array}$ & 11 \\
\hline 3 months & $\begin{array}{l}11 \cdot 0 \\
(1-132)\end{array}$ & 12 & $\begin{array}{l}12 \cdot 0 \\
(0-132)\end{array}$ & 12 & $\begin{array}{l}1 \cdot 0 \\
(0-8)\end{array}$ & 11 \\
\hline 6 months & $\begin{array}{l}10 \cdot 5 \\
(0-31)\end{array}$ & 12 & $\begin{array}{l}10 \cdot 0 \\
(0-31)\end{array}$ & 12 & $\begin{array}{l}1 \cdot 0 \\
(0-10)\end{array}$ & 11 \\
\hline 9 months & $\begin{array}{l}9 \cdot 0 \\
(0-71)\end{array}$ & 12 & $\begin{array}{l}9 \cdot 0 \\
(0-61)\end{array}$ & 12 & $\begin{array}{l}1.5 \\
(0-10)\end{array}$ & 11 \\
\hline 12 months & $\begin{array}{l}8 \cdot 5 \\
(0-30)\end{array}$ & 11 & $\begin{array}{l}9 \cdot 0 \\
(0-30)\end{array}$ & 11 & $\begin{array}{l}1 \cdot 5 \\
(0-6)\end{array}$ & 10 \\
\hline 15 months & $\begin{array}{l}8 \cdot 0 \\
(0-33)\end{array}$ & 11 & $\begin{array}{l}7 \cdot 0 \\
(0-33)\end{array}$ & 11 & $\begin{array}{l}4 \cdot 0 \\
(0-8)\end{array}$ & 10 \\
\hline 18 months & $\begin{array}{l}9 \cdot 0 \\
(0-40)\end{array}$ & 11 & $\begin{array}{l}11 \cdot 0 \\
(0-40)\end{array}$ & 11 & $\begin{array}{l}3 \cdot 0 \\
(1-7)\end{array}$ & 10 \\
\hline 21 months & $\begin{array}{l}13.5 \\
(3-40)\end{array}$ & 8 & $\begin{array}{l}13 \cdot 0 \\
(1-22)\end{array}$ & 8 & $\begin{array}{l}3 \cdot 5 \\
(0-7)\end{array}$ & 7 \\
\hline 24 months & $\begin{array}{l}11 \cdot 0 \\
(4-30)\end{array}$ & 7 & $\begin{array}{l}11 \cdot 0 \\
(3-23)\end{array}$ & 7 & $\begin{array}{l}1 \cdot 5 \\
(0-7)\end{array}$ & 6 \\
\hline
\end{tabular}

Values are median (range) per month. Patients were assessed every three months following completion of the double blind, placebo controlled, crossover trial. identified cognitive impairment with carbamazepine and phenytoin, ${ }^{22}$ it was not sensitive to the deleterious effects of vigabatrin.

With the exception of the memory tests, scores tended to be lower during treatment with vigabatrin although these differences were not statistically significant. This trend, however, cannot simply be ignored. There are considerable difficulties in measuring small changes in neuropsychological functioning in this patient population. Impairment due to epilepsy related factors, other than anticonvulsant drugs, can be identified when patients with epilepsy are contrasted with healthy controls. ${ }^{222325}$ Even standardised tests become less sensitive at the upper and lower ends of the scale, so that small changes in function become difficult to detect unless the sample size is large. Thus, the possibility that vigabatrin does impair cognitive performance cannot be excluded entirely, although it seems clear that any such effect must be small.

The most consistently reported side effect with vigabatrin is tiredness ${ }^{4}$ which, if marked, could reasonably be expected to influence some of the tasks in the battery. In this study, patients reported significantly greater sedation during weeks two and six of the treatment phase compared with the same number of weeks on placebo. Our data, however, revealed fewer significant correlations between sedation scores and performances in other tests during the vigabatrin phase than on the placebo, even though patients reported more sedation while taking the active drug. Hence sedation itself did not bring about impairment of cognitive performance. The difference between sedation score during the treatment phase and placebo phase at week zero was not statistically significant and was too small to be clinically significant. Interestingly, patients did not report sedation after six weeks' treatment with the higher vigabatrin dose. This supports the rapid development of tolerance to the sedative effect of this drug.

\section{LONG TERM RESULTS}

All three composite scales showed significant improvement during follow up in the 12 responders who took vigabatrin long term. The temporal history of these changes was inconsistent with a practice effect or with regression to the mean. If there had been a marked learning effect, it would have occurred during the first phases of the trial when the tests were administered eight times over 28 weeks.

Improvement in test scores in patients responding to vigabatrin continued during longer term follow up. If the drug brought about a small performance decrement, it is possible that tolerance developed during follow up and that this, together with an improvement in well being brought about by better seizure control, provides the explanation for this observation. Tolerance may not necessarily be a pharmacological phenomenon, but may simply reflect the patient's ability to adapt psychologically to slight, drug 
induced deterioration in functioning. It seems most likely, however, that the major factor responsible for the improvement was better seizure control.

In conclusion, the results of the short term part of the study suggest that treatment with vigabatrin did not produce significant cognitive impairment. Patients reported early sedation, but this had disappeared by the 12th week of treatment. Longer term follow up allowed the identification of a further small improvement in overall performance. The sustained reduction in seizure frequency may have contributed to its development. From the practical viewpoint, phased introduction of vigabatrin seems a prudent policy to permit tolerance to subjective sedation during early treatment.

Our grateful thanks go to Moya Dewar for expert secretarial assistance and to Marion Merrell Dow for supplying the drug and placebo and for financial support.

1 Editorial. Vigabatrin. Lancet 1989;1:532-3.

2 Mumford JP, Dam M. Meta-analysis of European placebo-controlled studies of vigabatrin in drug-resistant epilepsy. Br f Clin Pharmacol 1989;27(Suppl 1):S101-7.

3 Ring HA, Heller AJ, Farr IN, Reynolds EH. Vigabatrin rational treatment for chronic epilepsy. If Neurol Neurosurg Psychiatry 1990;53:1051-5.

4 Grant SM, Heel RC. Vigabatrin. Drugs 1991;41:889-926.

5 Michelucci R, Tassinari CA. Response to vigabatrin in relation to seizure type. $\mathrm{Br} \mathcal{F}$ Clin Pharmacol 1989;27(Suppl 1):S119-24.

6 Pedersen SA, Klosterkov P, Gram L, Dam M. Long-term study of gamma-vinyl GABA in the treatment of epilepsy. Acta Neurol Scand 1985;72:295-8

7 Sivenius MR, Ylinen A, Murros K, Matkainen $R_{\text {, }}$ Sivenius MR, Ylinen A, Murros $\mathrm{K}$, Matkainen $\mathbf{R}$,
Riekkinen P. Double-blind dose reduction study of vigabiekkinen P. Double-blind dose reduction study of vigabatrin in

8 Browne TR, Mattson RH, Penry JK, et al. Vigabatrin for refractory complex partial seizures: multicenter single blind study with long-term follow-up. Neurology 1987; 37:184-9.

9 Cocito L, Maffini M, Perfumo P, Roncallo F, Loeb C.
Vigabatrin in complex partial seizures: a long-term study. Epilepsy Res 1989;3:160-6.

10 Remy C, Beaumont D. Efficacy and safety of vigabatrin in the long-term treatment of refractory epilepsy. $\mathrm{Br} \mathcal{F} \mathrm{Clin}$ Pharmacol 1989;27(Suppl 1):S125-9.

11 Tartara A, Manni R, Galimberti CA, Mumford JP, Iudice A, Perucca E. Vigabatrin in the treatment of epilepsy: a long-term follow-up study. F Neurol Neurosurg Psychiatry $1989 ; 52: 467-71$

12 Dam M. Long-term evaluation of vigabatrin (gamma vinyl GABA) in epilepsy. Epilepsia 1989;30(Suppl 3):S26-30.

13 Sander JW, Trevisol-Bittencourt PC, Hart YM, Shorvon SD. Evaluation of vigabatrin as an add-on drug in the management of severe epilepsy. $\mathcal{f}$ Neurol Neurosurg Psychiatry 1990;53:1008-10.

14 Reynolds EH, Ring HA, Farr IN, Heller AJ, Elwes RD. Open, double-blind and long-term study of vigabatrin in chronic epilepsy. Epilepsia 1991;32:530-8.

15 Sivenius J, Ylinen A, Murros K, Mumford JP, Reikkinen PJ. Vigabatrin in drug-resistant partial epilepsy: a 5-year PJ. Vigabatrin in drug-resistant partial epileps
follow-up study. Neurology 1991;41:562-5.

16 Butler WH. The neuropathology of vigabatrin. Epilepsia 1989;30(Suppl 3):S15-17.

17 Gibson JP, Yarrington JT, Loudy DE, Gerbig CG, Hurst GH, Newberne JW. Chronic toxicity studies with vigabatrin, a GABA-transaminase inhibitor. Toxicol Pathol 1990;18:225-38

18 Agnosti T, Yasargil G, Egil M, Wieser HG, Wiestler OD. Neuropathology of a human hippocampus following long-term treatment with vigabatrin: lack of microvacuoles. Epilepsy Res 1990;6:166-70

19 Cannon DJ, Butler WH, Mumford JP, Lewis PJ. Neuropathologic findings in patients receiving longterm vigabatrin for chronic intractable epilepsy. $f$ Child term vigabatrin for chronic intract

20 McGuire AM, Duncan JS, Trimble MR. Effect of vigabatrin on cognitive function and mood when used as addon therapy in patients with intractable epilepsy Epilepsia 1992;33:128-34.

21 Gillham RA, Williams N, Wiedmann K, Butler E, Larkin JG, Brodie MJ. Concentration-effect relationships with carbamazepine and its epoxide on psychomotor and cognitive function in epileptic patients. $f$ Neurol Neurosurg Psychiatry 1988;51:929-33.

22 Gillham $R$, Williams $N$, Wiedmann $K$, Butler $E$, Larkin JG, Brodie MJ. Cognitive function in adult epileptic patients established on anticonvulsant monotherapy. Epilepsy Res 1990;7:219-25.

23 Gillham RA, Read CL McKee PJW, Larkin JG, Brodie MJ. Cognitive function in adult epileptic patients on MJ. Cognitive function in adult epileptic patients on

24 Brodie MJ, McKee PJW. Vigabatrin and psychosis. Lancet 1990;335:1279.

25 Brodie MJ, McPhail E, Macphee GJA, Larkin JG, Gray JMB. Psychomotor impairment and anticonvulsant therapy in adult epileptic patients. Eur $f$ Clin Pharmacol 1987;31:655-60.

\section{Historical description of primary writer's tremor}

Tremor elicited by writing may be a feature of several neurological diseases. In rare occasions it presents as a unique symptom, and its independent nosological identity is frequently discussed. In other patients it is combined with essential tremor ${ }^{1}$ or focal dystonia. ${ }^{2}$ The modern description of this entity corresponds to Rothwell, Traub and Marsden. ${ }^{3}$ However, we have encountered a description by Grisolle ${ }^{4}$ in 1848 that exactly resembles writer's tremor: "The affection consists of a particular tremor of the right hand fingers only observed when writing, and absent in all other circumstance. The patient is able to cut the pen and hold it with his fingers a long while, as if he were to write; he is able to wash himself, shave and play piano without difficulty. But as soon as he begins to write he is affected by tremor. When writing is interrupted, tremor ceases. On many ocasions patients do not experience discomfort or pain. In others, these do exist."

"This affection seems to develop slowly; until now it has only been observed in males and all were above the age of 30."

"Alcohol spirits, moral affections and seminal losses are all believed to increase the tremor. The symptoms have never been ascribed to a certain disease; therefore, it has been compared with chorea."
Although this description probably also includes patients with writer's cramp, the mention of absence of uncomfortable or painful sensations and male predominance refers, undoubtedly, to primary writer's tremor.

$$
\begin{array}{r}
\text { J CASTILLO } \\
\text { FMARTINEZ } \\
\text { A GONZÁLEZ-QUINTELA } \\
\text { M NOYA } \\
\text { Servicio de Neurologia, } \\
\text { Hospital General de Galicia-Clinico Universitario, }
\end{array}
$$
Santiago de Compostela, Spain

Correspondence to: Professor J Castillo, Servicio de Neurología, Hospital General de Galicia-Clínico Universitario, Santiago de Compostela, Spain.

1 Kachi T, Rothwell JC, Cowan JMA, Marsden CD. Writing tremor: its relationship to benign essential tremor. $f$ Neurol Neurosurg Psychiatry 1985;48:545-50. 2 Elble RJ, Moody C, Higgins C. Primary writing tremor. A form of focal dystonia? Mov Disord 1990;5:118-26.

3 Rothwell JC, Traub MM, Marsden CD. Primary writing tremor. $f$ Neurol Neurosurg Psychiatry 1979;42: 1106-14.

4 Grisolle A. Tratado de Patologia Interna. Tomo sesto. De las neurosis. Madrid: Imprenta de Francisco Andrés y Compañía, 1848:93-4. 